\title{
Genetic Testing of Epileptic Encephalopathies of Infancy: An Approach
}

\author{
Suvasini Sharma, Asuri N. Prasad
}

\begin{abstract}
The epileptic encephalopathies of infancy are a group of disorders characterized by intractable seizures, persistent abnormality of cortical function documented on EEG, and consequently impaired neuro-developmental outcomes. The etiologies vary and include; structural brain malformations, acquired brain insults, and inborn errors of metabolism in the majority of the affected patients. In a proportion of these cases no obvious etiology is identifiable on investigation. Recent advances in molecular diagnostics have led to the discovery of a number of gene defects that may be causal in many epileptic encephalopathies. Identification of the causative mutation is important for prognostic and genetic counseling, and may also carry treatment implications. The recently described genes include; Cyclin-Dependent Kinase-Like 5 gene (CDKL5), Protocadherin 19 (PCDH19), Sodium channel neuronal type 1a subunit gene (SCN1A), Aristaless-Related Homeobox Gene (ARX), and Syntaxin binding protein 1 gene (STXBP1), amongst others. Distinct electro-clinical syndromes are increasingly being identified amongst patients carrying the various mutations. In this review, we outline the approach to clinical evaluation and genetic testing of epileptic encephalopathies in infancy.
\end{abstract}

RÉSUMÉ: Démarche concernant les tests génétiques pour les encéphalopathies épileptiques de la petite enfance. Les encéphalopathies épileptiques de la petite enfance sont un groupe de maladies caractérisées par des crises convulsives réfractaires au traitement médical et des anomalies de la fonction corticale persistantes, documentées par l'ÉEG, avec comme conséquence des troubles du développement neurologique. Leur étiologie est variable : malformations cérébrales structurales, lésions cérébrales acquises et erreurs innées du métabolisme chez la plupart des patients. Chez une certaine proportion des patients, la recherche d'une étiologie identifiable demeure vaine. Des progrès récents dans le domaine du diagnostique moléculaire ont permi de découvrir un certain nombre de défauts génétiques qui peuvent être en cause dans plusieurs encéphalopathies épileptiques. L'identification de la mutation causale est importante pour le pronostic et le conseil génétique et peut également avoir une incidence sur le traitement. Voici quelques uns des gènes décrits récemment : CDKL5, PCDH19, SCN1A, ARX et STXBP1. Des syndromes électro-cliniques distincts sont de plus en plus identifiés chez les patients porteurs de différentes mutations. Dans cette revue, nous exposons brièvement comment aborder l'évaluation clinique et génétique des encéphalopathies épileptiques de la petite enfance.

Can J Neurol Sci. 2013; 40: 10-16

Epileptic encephalopathies are disorders in which the combination of frequent and severe seizures along with the unremitting interictal paroxysmal epileptiform activity contributes to progressive neurological deterioration ${ }^{1}$. Several epileptic encephalopathies have been described in infancy based on their electroclinical features [age of onset, seizure type, and electroencephalogram (EEG) pattern]. These include; Ohtahara syndrome, early myoclonic encephalopathy, epilepsy of infancy with migrating focal seizures, West syndrome, and Dravet syndrome.

The etiologies of epileptic encephalopathies are heterogeneous and a significant proportion of cases are attributable to structural brain defects and inherited metabolic disorders. However, in several instances of an epileptic encephalopathy a pathogenic gene mutation has been identified even when no clear genetic inheritance patterns or consanguinity exist. As this is an evolving field, the genotype-phenotype correlations are not well understood, and there is considerable phenotypic variability within the same genetic defect; e.g. mutations in the sodium channel genes cause Dravet syndrome, as well as generalized epilepsy with febrile seizure plus. A particular electroclinical syndrome may be caused by multiple genetic defects. For example, Ohtahara syndrome may be caused by mutations in syntaxin binding protein-1 $(\text { STXBP-1 })^{2}$, Aristaless related homeobox $(A R X)^{3}$, and Solute carrier family 25 member 22 (SLC25A22) gene encoding a mitochondrial glutamate carrier ${ }^{4}$.

During the evaluation of a child with an epileptic encephalopathy when no apparent cause is obvious on the basis of an initial clinical evaluation, normal neuroimaging and negative results on metabolic screening, other genetic etiologies need to be considered. Identification of a specific gene defect carries significant benefits, namely in providing genetic counseling, and avoiding the delays, costs and inconvenience of

\footnotetext{
From the Department of Pediatrics (SS), Lady Hardinge Medical College, New Delhi, India; Department of Pediatrics (ANP), Schulich School of Medicine and Dentistry, Children's Hospital of Western Ontario, London, Ontario, Canada.

Received May 15, 2012. Final Revisions Submitted July 12, 2012.

Correspondence to: Asuri N Prasad, Department of Pediatrics, Schulich School of

Medicine and Dentistry, Children's Hospital of Western Ontario, London, Ontario,

Canada. Email: narayan.prasad@1hsc.on.ca.
} 
invasive investigations such as liver, muscle and skin biopsies which are often resorted to in such instances ${ }^{5}$. Such information can influence the choice of anti-epileptic treatments. A confirmed diagnosis will provide an answer to parents who may have attributed the epileptic encephalopathy to another incidental factor such as immunization, and even closure when the condition is fatal ${ }^{6}$. Furthermore, the discovery of the molecular genetic basis in addition aids understanding of pathophysiological mechanisms and pathways in the different epileptic encephalopathies.

In this article, we outline the approach to the genetic testing of an infant with epileptic encephalopathies and emphasize the clinical aspects that guide the clinician towards the appropriate test.

\section{Epileptic encephalopathies in infants}

The electroencephalographic findings in infants with epileptic encephalopathies are known to have an age-dependent expression, depending on the degree of brain maturation ${ }^{7}$. For example, the EEG may show a burst-suppression pattern in the neonatal period, hypsarrhythmia in infancy, and evolution to multifocal or generalized slow spike-wave discharges in early childhood with poor organization of background rhythms. The electro-clinical features of the common infantile epileptic encephalopathies are summarized in Table 1. The etiology may be known (brain malformations, acquired brain insults, chromosomal abnormalities, inherited metabolic disorders, neurocutaneous syndromes such as tuberous sclerosis) or cryptogenic.

\section{Neonatal epileptic encephalopathies with burst suppression}

In newborns, two syndromes are well characterized: early myoclonic encephalopathy (EME) and Ohtahara syndrome (also called Early infantile epileptic encephalopathy $)^{8}$. Both are characterized by a burst suppression pattern on EEG. Early myoclonic encephalopathy typically presents in the first few days of life. These infants have mixed seizures; erratic or fragmentary myoclonus, focal seizures, and tonic seizures ${ }^{8}$. The EEG shows a burst suppression pattern that is prominent during sleep, but may disappear in the awake state. Frequently encountered in this setting are inherited metabolic disorders including; non-ketotic hyperglycinemia, organic acidemias, Menke's disease, Zellweger syndrome, and molybdenum cofactor deficiency ${ }^{9}$. Pyridoxine dependency has also been described as an etiology ${ }^{10}$. There are no known causative genes at present.

Table 1: Electro-clinical characteristics and etiologies of epileptic encephalopathies in infancy

\begin{tabular}{|c|c|c|c|c|c|}
\hline $\begin{array}{l}\text { Epilepsy } \\
\text { syndrome }\end{array}$ & Age at onset & Seizure type & EEG findings & Etiology & $\begin{array}{l}\text { Associated Genetic } \\
\text { etiologies }\end{array}$ \\
\hline $\begin{array}{l}\text { Early myoclonic } \\
\text { encephalopathy }\end{array}$ & $\begin{array}{l}\text { First few days } \\
\text { or weeks of } \\
\text { life }\end{array}$ & $\begin{array}{l}\text { Erratic myoclonus, } \\
\text { focal seizures, and } \\
\text { tonic seizures }\end{array}$ & $\begin{array}{l}\text { Burst suppression } \\
\text { pattern, } \\
\text { predominantly in } \\
\text { sleep }\end{array}$ & $\begin{array}{l}\text { Inherited metabolic disorders (NKH, } \\
\text { organic acidemias, Menke's disease, } \\
\text { Zellweger syndrome, molybdenum } \\
\text { cofactor deficiency, Pyridoxine } \\
\text { dependency }\end{array}$ & \\
\hline $\begin{array}{l}\text { Ohtahara } \\
\text { syndrome }\end{array}$ & $\begin{array}{l}\text { First few days } \\
\text { or weeks of } \\
\text { life }\end{array}$ & $\begin{array}{l}\text { Tonic spasms, either } \\
\text { singly or in clusters, } \\
\text { Focal seizures }\end{array}$ & $\begin{array}{l}\text { Burst suppression } \\
\text { pattern both in sleep } \\
\text { and wake states }\end{array}$ & $\begin{array}{l}\text { Brain malformations such as cortical } \\
\text { dyspasia, hemimegalencephaly, and } \\
\text { Aicardi syndrome }\end{array}$ & $\begin{array}{l}\text { STXBP-1,ARX, } \\
S L C 25 A 22\end{array}$ \\
\hline $\begin{array}{l}\text { Epilepsy of } \\
\text { infancy with } \\
\text { migrating focal } \\
\text { seizures }\end{array}$ & $\begin{array}{l}\text { First few days } \\
\text { or weeks of } \\
\text { life }\end{array}$ & $\begin{array}{l}\text { Focal seizures arising } \\
\text { independently from } \\
\text { both hemispheres }\end{array}$ & $\begin{array}{l}\text { Interictal multifocal } \\
\text { discharges, migrating } \\
\text { ictal paroxysmal } \\
\text { rhythms }\end{array}$ & Unknown; suspected genetic & $S C N 1 A, P L C B 1$ \\
\hline West syndrome & 3-12 months & Infantile spasms & Hypsarrhythmia & $\begin{array}{l}\text { Perinatal brain injury, intra-uterine } \\
\text { infections, inherited metabolic } \\
\text { disorders, neurocutanoeous } \\
\text { syndromes, brain malformations, } \\
\text { post-natal acquired brain insults }\end{array}$ & $\begin{array}{l}C D K L-5, A R X, \\
S T X B P-1, P L C B 1\end{array}$ \\
\hline Dravet syndrome & $\begin{array}{l}\text { First year of } \\
\text { life }\end{array}$ & $\begin{array}{l}\text { Initially generalized } \\
\text { or partial seizures } \\
\text { with fever, Later, } \\
\text { myoclonus, atypical } \\
\text { absences and partial } \\
\text { seizures are noted. }\end{array}$ & $\begin{array}{l}\text { Initially normal, later } \\
\text { generalized spike } \\
\text { wave and polyspike } \\
\text { wave discharges. }\end{array}$ & Genetic & $\begin{array}{l}\text { SCN1A, PCDH 19, } \\
\text { GABRG2, SCN1B }\end{array}$ \\
\hline
\end{tabular}

ARX: Aristaless-Related Homeobox Gene, $C D K L-5$ : Cyclin-Dependent Kinase-Like 5 gene, SLC25A22: Solute carrier family 25 member 22 gene, STXBP1: Syntaxin binding protein 1 gene, SCN1A: Sodium channel neuronal type 1a subunit gene, PCDH19: Protocadherin 19 gene, PLCB1: phospholipase C- $\beta 1$ gene, SCN1B: Sodium channel neuronal type $1 \beta$ subunit gene, $G A B R G 2$ : gamma aminobutyric acid type A receptor gamma 2 subunit gene 
Ohtahara syndrome typically has an onset within the first few days or weeks of life with predominant tonic spasms, that may be single, or occur in clusters. These occur both in sleep and waking states. Focal seizures also occur in one third to one half of the patients 9 . The EEG shows a burst suppression pattern that is persistent across sleep-wake cycles. The most frequently reported associations are brain malformations such as focal cortical dysplasia, hemimegalencephaly, and Aicardi syndrome ${ }^{11}$. Other gene defects that have been identified in these patients include; mutations in the syntaxin binding protein-1 $(S T X B P-1)^{2}$, Aristaless related homeobox $(A R X)^{3}$, and $S L C 25 A 22$ gene encoding a mitochondrial glutamate carrier ${ }^{4}$.

A similar epileptic encephalopathy attributable to mutations in the potassium channel $K C N Q 2$ gene that encodes the voltage gated potassium channel Kv7.2 has been recently described ${ }^{12}$. These infants experienced intractable seizures in the first week of life with a prominent tonic component. Seizures generally resolved by age three years but the children were left with severe, intellectual disability and motor impairment. The EEG at onset showed a burst-suppression pattern or multifocal epileptiform activity. Early magnetic resonance imaging (MRI) of the brain showed characteristic hyperintensities in the basal ganglia and thalamus that later resolved ${ }^{12}$. Though the condition appears similar to Ohtahara syndrome, subtle differences include; progression with reduction in seizure frequency in $K C N Q 2$ encephalopathy in comparison to Ohtahara syndrome which frequently evolves to West syndrome, and the unusual occurrence of transient basal ganglia imaging abnormalities in $K C N Q 2$ encephalopathy.

\section{Epilepsy of infancy with migrating focal seizures (Formerly called malignant migrating partial seizures of infancy)}

This condition is characterized by normal early development, refractory focal seizures arising independently from both hemispheres and severe psychomotor retardation and a poor $\operatorname{prognosis}^{13}$. Mutations in the SCN1A gene encoding the alpha-1 subunit of the sodium channel were found in 2 out of 15 patients with this condition in a recent study ${ }^{14}$. Freilich et al have also reported a case of epilepsy of infancy with focal migrating seizures with a novel SCN1A mutation ${ }^{15}$. Recently, a homozygous deletion in the phospholipase $\mathrm{C} \beta 1(P C B 1)$ gene has also been described in a child with this epilepsy syndrome ${ }^{16}$.

\section{West syndrome}

West syndrome is characterized by the occurrence of infantile spasms, EEG finding of hypsarrhythmia, and developmental delay or regression ${ }^{17}$. Infantile spasms typically occur between 3 to 12 months-of-age. Spasms usually occur in clusters comprising of tonic contractions of limb and axial muscles, and may be flexor, extensor or mixed. The spasms typically occur in relation to the sleep wake cycle; they occur when the child wakes up from sleep, or is going to sleep. The etiology is diverse. Any insult to the developing brain (perinatal brain insult, intra-uterine infections, inherited metabolic disorders, neurocutaneous syndromes, brain malformations, post-natal acquired brain insults (e.g. meningoencephalitis, hypoxic brain injury) during a critical vulnerable time window can lead to West syndrome. In as many as $30 \%$ of the affected children, no cause can be identified, and in these cases pathogenic gene mutations are now being shown to play a causal role. Gene defects which have been associated with West syndrome include cyclin dependent kinase5 like gene $(C D K L-5)$ mutations ${ }^{18}, A R X^{19}, S T X B P-1^{20}$, SPTAN1 encoding $\alpha$-II spectrin ${ }^{21}$, and phospholipase C- $\beta 1$ mutations ${ }^{22}$.

\section{Dravet syndrome}

Dravet syndrome is characterized by the occurrence of generalized or unilateral clonic or tonic-clonic seizures, usually triggered by fever, in the first year of life of a previously normal infant $^{23}$. Later, other types of seizures are reported, including myoclonus, atypical absences and partial seizures. Early development is normal and slows in the second year of life. Cognitive decline and behavioral disturbances are frequently noted.

Neurological signs consisting of hypotonia, ataxia, pyramidal signs, and motor in- coordination may also be seen. A positive family history is noted in $25 \%-71 \%$ of patients ${ }^{23}$. The inter-ictal EEG is usually normal in the first year of life. Between the second and the fifth years of life, a progressive increase in paroxysmal epileptiform abnormalities with background slowing is evident in more than $50 \%$ of the cases on the EEG ${ }^{24}$. Paroxysmal EEG abnormalities are constituted by generalized spike wave and polyspike wave discharges. Focal and multifocal abnormalities such as fast spikes or polyspikes are also described. Mutations in the SCN1A gene encoding the alpha-1 subunit of the sodium channel are detectable in $70-80 \%$ of patients with Dravet syndrome ${ }^{25}$. Rarely mutations have been identified in the gamma aminobutyric acid type A receptor gamma 2 subunit gene $(G A B A R G 2)$ and Sodium channel neuronal type $1 \beta$ subunit gene $(S C N 1 B)$ genes ${ }^{25}$. The most significant aspect of the molecular genetic basis is that most of these mutations occur de novo, and the absence of a family history or a Mendelian pattern of inheritance is not a necessary prerequisite for testing ${ }^{25}$.

Mutations associated with PCDH19 (Protocadherin 19 gene) have also been associated with a Dravet-like syndrome in girls ${ }^{26}$. Mutations of $P C D H 19$ were originally described with the disorder called 'epilepsy with mental retardation limited to females' (EFMR) ${ }^{27}$. This disorder is characterized by seizure onset in infancy or early childhood (6-36 months) and cognitive impairment. The disorder is X-linked with an unusual expression pattern and with the phenotype being restricted to females; carrier males remain apparently unaffected, with normal cognitive function.

Dravet-like syndrome caused by PCDH19 mutations and and SCN1A mutation-associated Dravet syndrome patients share several feature ${ }^{28}$. These include normal development before seizure onset, early onset of seizures (before age one year), association of febrile and afebrile seizures, with a high susceptibility of the seizures to being triggered by fever, occurrence of hemiclonic or unilateral seizures, and later generalized tonic-clonic seizures, seizures occurring in clusters, prolonged seizures, and ultimately development of psychomotor regression. The $\mathrm{PCDH} 19$ mutation affected patients however, present with a later mean age of onset (nine months compared with six months), fewer absence and myoclonic seizures, and the condition carries a slightly better developmental outcome. Also photosensitivity, which is very common in Dravet syndrome, is unusual in $\mathrm{PCDH} 19$ patients. 
The appropriate diagnosis of Dravet syndrome is important as it has therapeutic implications. Lamotrigine, phenytoin, carbamazepine, and vigabatrin may worsen the seizures, and their use should be avoided. Treatments with a beneficial effect include sodium valproate, stiripentol, topiramate, benzodiazepines, and the ketogenic $\operatorname{diet}^{29}$.

\section{Clinical evaluation of an infant with epileptic encephalopathy}

The evaluation begins with a detailed history, which should include details of the pregnancy, delivery and postnatal factors. History of excessive fetal movements must be elicited; these could signify the presence of fetal seizures, which are seen in pyridoxine dependency ${ }^{30}$. Intra-uterine onset of seizures has also been described in $K C N Q 2$ epileptic encephalopathy ${ }^{12}$. A history of prematurity is common in pyridoxal phosphate responsive seizures $^{30}$. The age of onset of the seizures, the type of seizures and relationship with the sleep wake cycle provide additional help in seizure and syndrome classification. History of excessive irritability and vomiting, multisystem symptoms are also frequently reported in pyridoxine dependency. The sex of the child is also important, as epileptic encephalopathies associated with CDKL-5 mutations, and PCDH19 mutations are seen in girls, while the ones associated with $A R X$ mutations are seen in boys. However, recently mutations in the $C D K L-5$ gene have been described in epileptic encephalopathy in boys as well ${ }^{31}$. A detailed family history and a three-generation pedigree should be constructed.

A history of seizures being precipitated by fever is characteristic in patients with Dravet syndrome and PCDH19 related mutations. The developmental history is important to elucidate the pattern of development prior to the onset of seizures (normal or pre-existing developmental delay). Information about developmental arrest or regression after the onset of seizures is of critical importance. The presence of autistic features and hand stereotypies (Rett like phenotype) is seen in epileptic encephalopathy associated with $C D K L-5$ mutations ${ }^{32}$. The presence of other neurological problems such as stiffness, vision and hearing problems must be screened for.

A general physical examination must be performed to look for craniofacial dysmorphic features (chromosomal abnormalities, peroxisomal disorders, abnormal fat pads in congenital disorders of glycosylation), and neurocutaneous markers such as ash leaf macules, which are characteristic of tuberous sclerosis. Presence of ambiguous genitalia in a child with infantile spasms is an indication to screen for $A R X$ mutations ${ }^{19}$.

The neurological examination must be performed to assess tone abnormalities, and associated movement disorders such as dystonia, choreoathetosis, and stereotypies. The presence of dystonias and progressive spasticity in a child with infantile spasms may be a clue towards an underlying $A R X$ mutation $^{33}$. The ocular fundi must be examined for the presence of chorioretinitis and or changes of a pigmentary retinopathy, optic atrophy, which may point towards the presence of infantile neuronal ceroid lipo-fuchsinosis, and mitochondriopathies.

\section{Investigations}

Investigation of a child with a suspected epileptic encephalopathy begins with an EEG. A video-EEG is preferable over a routine EEG, especially if there are very frequent seizures. A sleep and awake record must be obtained, lasting 4560 minutes, in order not to miss abnormalities. Some abnormalities such as burst suppression pattern in early myoclonic encephalopathy and hypsarrhythmia may change with the sleep wake cycle, hence both states must be sampled. Photic stimulation must be done, as it is frequently elicits abnormal photoparoxysmal responses in Dravet syndrome and infantile neuronal ceroid lipofuchsinosis.

The inter-ictal EEG can be diagnostically useful in Ohtahara syndrome, early myoclonic encephalopathy, and West syndrome. However, in Dravet syndrome, the EEG performed during the first year of life is usually normal. The EEG shows generalized spike and polyspike wave discharges from two to five years-ofage.

A video-EEG defines and clarifies seizure semiology, and can identify persistent focal features that may point towards potentially surgically remediable causes, and will establish whether many paroxysmal events (which are common in these children) are seizures, or non-epileptic movements. At times, a particular seizure semiology may be of diagnostic value; for instance, a distinct seizure type, the hypermotor-tonic-spasms sequence has been described in association with CDKL5 mutations $^{34}$.

A neuroimaging study, preferably an MRI of brain, must be performed in all children with epileptic encephalopathy. Magnetic resonance imaging is often diagnostic for brain malformations, tuberous sclerosis, perinatal insult sequelae such as asphyxia, while an MR spectroscopy performed simultaneously can be of diagnostic value in patients with inborn errors of metabolism (glycine encephalopathy, creatine deficiency syndromes), and mitochondriopathies (elevated lactate). Genetic epileptic encephalopathies associated with $A R X$ mutations may have brain malformations such as hydranencephaly, lissencephaly (more severe in the posterior regions), or agenesis of the corpus callosum ${ }^{19}$. Severe cerebral hypomyelination has been seen in West syndrome associated with SPTAN1 mutations ${ }^{21}$. However, in the majority of the genetic epileptic encephalopathies, the MRI is normal or may show non-specific features such as cerebral atrophy or delayed myelination. The presence of a cortical dysgenesis should not preclude a genetic or metabolic etiology as is increasingly being recognized.

Chromosomal karyotyping must be performed if dysmorphic features are present. If no clue has been found by clinical evaluation, and neuroimaging, metabolic etiology must be looked for, especially keeping in mind treatable conditions. If the initial metabolic investigations exclude hypoglycemia, hypocalcemia, hypomagnesemia, elevations of lactate and ammonia, the focus of investigation and management should continue to vigorously search for treatable epileptic encephalopathies. Methylene tetrahydrofolate reductase and biotinidase deficiency must be screened for $^{35}$. A cerebrospinal fluid (CSF) examination must be performed to look for low glucose levels and low CSF to serum glucose ratio (glucose transporter defect), elevated lactate (mitochondriopathies), 
elevated glycine (non-ketotic hyperglyciemia), serine (serine biosynthesis defects), or pipecolic acid (pyridoxine dependency), and neurotransmitters (abnormalities seen in Pyridoxal phosphate dependency) ${ }^{36}$.

Some authorities recommend a sequential therapeutic trial with vitamin B6, pyridoxal phosphate and folinic acid should be instituted early in all babies with epileptic encephalopathy and poor response to antiepileptic treatment. The reader is referred to a recent article on the metabolic evaluation and management of pyridoxine dependent epilepsy (antiquitin deficiency) for rationale and additional details ${ }^{36}$.

A protocol for targeted and selective genetic testing can be developed based on the clinical characteristics of epileptic encephalopathy and the seizure phenotype, and a syndromic diagnosis. In this context, the decision and selection of genetic testing is guided by several principles that take into account the many ramifications of a particular clinical scenario ${ }^{37}$. These principles have been discussed in the document produced by the ILAE genetics commission ${ }^{38}$. In the examples discussed where the gene defect is known, a targeted mutation analysis would carry great clinical utility as pointed out in the commission document. The various epileptic syndromes associated with genetic mutations and their clinical characteristics are detailed in Table 2. Testing of SCN1A mutations must be done in patients with Dravet syndrome. In girls with suspected Dravet syndrome, if SCN1A mutations are not present, testing for PCDH19 mutations should be performed. Testing for SCN1A mutations may also be considered in children with migrating partial seizures of infancy, and severe infantile multifocal epilepsy ${ }^{14,39}$.

In babies with Ohtahara syndrome, early myoclonic encephalopathy, and non-syndromic neonatal onset epileptic encephalopathies, testing for STXBPI mutations must be performed, once brain malformations or inherited metabolic defects have been excluded ${ }^{40}$. There will be an ensuing debate as to whether molecular testing should precede screening for metabolic disorders. The costs of molecular diagnostics under current conditions would favor the exclusion of structural brain malformations and treatable metabolic disorders first.

In children with West syndrome with detected etiology, testing for $C D K L-5$ mutations must be considered in girls with early onset seizures, autistic features, and hand stereotypies. $A R X$ mutations must be tested in the presence of $\mathrm{X}$-linked inheritance, and/or ambiguous genitalia.

In instances where no definite syndromic diagnosis is made or the targeted testing excludes the known gene defects, further genetic testing and its diagnostic yield remains unclear. This involves testing for copy number variations by single nucleotide polymorphism (SNP) microarray, genomic imbalances using array comparative genomic hybridization $(\mathrm{CGH})^{41}$ and evolving 3rd generation high throughput sequencing technologies using exome sequencing ${ }^{41}$. Chromosomal microarray (arrayCGH) is now recommended as a first-tier test in patients with unexplained developmental delay, intellectual disability, autism spectrum disorders, or multiple congenital anomalies ${ }^{42}$. There is emerging

Table 2: Clinical features and epilepsy syndromes associated with genetic epileptic encephalopathies

\begin{tabular}{|c|c|c|}
\hline$C D K L-5$ & $\begin{array}{l}\text { West syndrome, typical seizure type- } \\
\text { hypermotor-tonic-spasms }\end{array}$ & $\begin{array}{l}\text { Affects girls, onset between 1-10 weeks of life, autistic features, hand } \\
\text { stereotypies, developmental delay, motor dyspraxia }\end{array}$ \\
\hline$A R X$ & $\begin{array}{l}\text { West syndrome, Ohtahara syndrome, } \\
\text { myoclonic epilepsy }\end{array}$ & $\begin{array}{l}\text { Affects males, developmental delay, intractable seizures, and } \\
\text { ambiguous genitalia, brain malformations may be associated. }\end{array}$ \\
\hline SLC25A22 & Ohtahara syndrome & $\begin{array}{l}\text { Epileptic spasms and focal seizures associated with suppression burst } \\
\text { beginning in the first days of life, microcephaly, hypotonia }\end{array}$ \\
\hline$S C N 1 A$ & $\begin{array}{l}\text { Dravet syndrome, migrating partial } \\
\text { seizures of infancy, severe multifocal } \\
\text { epilepsy of infancy }\end{array}$ & $\begin{array}{l}\text { Occurrence of generalized or unilateral clonic or tonic-clonic seizures, } \\
\text { usually triggered by fever, in infancy. Later, other types of seizures } \\
\text { occur, including myoclonus, atypical absences and partial seizures }\end{array}$ \\
\hline PCDH 19 & $\begin{array}{l}\text { Dravet syndrome, Epilepsy with } \\
\text { mental retardation limited to females } \\
\text { (EFMR) }\end{array}$ & $\begin{array}{l}\text { Same as SCN1A associated Dravet syndrome, Affects girls, Implicated } \\
\text { in X-linked mental retardation with epilepsy in girls }\end{array}$ \\
\hline
\end{tabular}

( $A R X$ - Aristaless-Related Homeobox Gene, CDKL-5- Cyclin-Dependent Kinase-Like 5 gene, SLC25A22- Solute carrier family 25 member 22 gene, STXBP1-Syntaxin binding protein 1 gene, SCN1A-Sodium channel neuronal type 1a subunit gene, $P C D H 19$ - Protocadherin 19 gene ) 
data on the role of copy number variations in epileptic encephalopathies ${ }^{43,44}$. In a recent study, out of 315 patients with epileptic encephalopathies, $7.9 \%$ were found to have rare copy number variations ${ }^{43}$. However, molecular karyotyping methods are yet to find widespread clinical application and utility in the field of epileptic encephalopathies. This field is rapidly evolving and will continue to generate additional susceptibility genes of interest $^{44}$.

\section{Conclusion}

Epileptic encephalopathies in infants and young children are caused by structural brain malformations, acquired brain insults, and inborn errors of metabolism in the majority of the affected patients. However no cause can be identified in a significant number of children. Recent advances in molecular diagnostics have led to the discovery of a number of genetic defects that may be causative in many epileptic encephalopathies. Most of these disorders are relatively rare and it will be a while before sufficient testing and experience will be available to formulate evidence-based guidelines. Identification of the causative mutation is important for prognostication and genetic counseling, and as has been discussed, provides a sound basis for treatment decisions and symptom management. Knowledge of the clinical profile, seizure types, and EEG features of the disease phenotype associated with the specific mutation as described above help the clinician improve diagnostic precision and management. Over time, large scale studies involving multicenter databases and rare disorder registries may capture the relative prevalence of these rare disorders in populations to provide evidence based data to make informed decisions.

\section{REFERENCES}

1. Nabbout R, Dulac O. Epileptic encephalopathies: a brief overview. J Clin Neurophysiol. 2003;20:393-7.

2. Saitsu H, Kato M, Mizuguchi T, et al. De novo mutations in the gene encoding STXBP1 (MUNC18-1) cause early infantile epileptic encephalopathy. Nat Genet. 2008;40:782-8.

3. Sartori S, Polli R, Bettella E, et al. Pathogenic role of the X-linked cyclin-dependent kinase-like 5 and aristaless-related homeobox genes in epileptic encephalopathy of unknown etiology with onset in the first year of life. J Child Neurol. 2011;26:683-91.

4. Molinari F, Kaminska A, Fiermonte G, et al. Mutations in the mitochondrial glutamate carrier SLC25A22 in neonatal epileptic encephalopathy with suppression bursts. Clin Genet. 2009;76: 188-94.

5. Scheffer IE. Genetic testing in epilepsy: what should you be doing? Epilepsy Curr. 2011;11:107-11.

6. Berkovic SF, Harkin L, McMahon JM, et al. De-novo mutations of the sodium channel gene SCN1A in alleged vaccine encephalopathy: a retrospective study. Lancet Neurol. 2006;5: 488-92.

7. Donat JF. The age-dependent epileptic encephalopathies. J Child Neurol. 1992;7:7-21.

8. Yamamoto H, Okumura A, Fukuda M. Epilepsies and epileptic syndromes starting in the neonatal period. Brain Dev. 2011;33: 213-20.

9. Ohtahara S, Yamatogi Y. Epileptic encephalopathies in early infancy with suppression-burst. J Clin Neurophysiol. 2003;20: 398-407.

10. Wang PJ, Lee WT, Hwu WL, et al. The controversy regarding diagnostic criteria for early myoclonic encephalopathy. Brain Dev. 1998;20:530-5

11. Yamatogi Y, Ohtahara S. Early-infantile epileptic encephalopathy with suppression-bursts, Ohtahara syndrome; its overview referring to our 16 cases. Brain Dev. 2002;24:13-23.
12. Weckhuysen S, Mandelstam S, Suls A, et al. KCNQ2 encephalopathy: emerging phenotype of a neonatal epileptic encephalopathy. Ann Neurol. 2012;71:15-25.

13. Coppola G. Malignant migrating partial seizures in infancy: an epilepsy syndrome of unknown etiology. Epilepsia. 2009;50 Suppl 5:49-51.

14. Carranza Rojo D, Hamiwka L, McMahon JM, et al. De novo SCN1A mutations in migrating partial seizures of infancy. Neurology. 2011;77:380-3.

15. Freilich ER, Jones JM, Gaillard WD, et al. Novel SCN1A mutation in a proband with malignant migrating partial seizures of infancy. Arch Neurol. 2011;68:665-71.

16. Poduri A, Chopra SS, Neilan EG, et al. Homozygous PLCB1 deletion associated with malignant migrating partial seizures in infancy. Epilepsia. 2012;53:e146-50.

17. Lux AL, Osborne JP. A proposal for case definitions and outcome measures in studies of infantile spasms and West syndrome: consensus statement of the West Delphi group. Epilepsia. 2004;45:1416-28.

18. Archer HL, Evans J, Edwards S, et al. CDKL5 mutations cause infantile spasms, early onset seizures, and severe mental retardation in female patients. J Med Genet. 2006;43:729-34.

19. Suri M. The phenotypic spectrum of ARX mutations. Dev Med Child Neurol. 2005;47:133-7.

20. Otsuka M, Oguni H, Liang JS, et al. STXBP1 mutations cause not only Ohtahara syndrome but also West syndrome--result of Japanese cohort study. Epilepsia. 2010;51:2449-52.

21. Saitsu H, Tohyama J, Kumada T, et al. Dominant-negative mutations in alpha-II spectrin cause West syndrome with severe cerebral hypomyelination, spastic quadriplegia, and developmental delay. Am J Hum Genet. 2010;86:881-91.

22. Kurian MA, Meyer E, Vassallo G, et al. Phospholipase C beta 1 deficiency is associated with early-onset epileptic encephalopathy. Brain. 2010;133:2964-70.

23. Dravet C. The core Dravet syndrome phenotype. Epilepsia. 2011;52 Suppl 2:3-9.

24. Bureau M, Dalla Bernardina B. Electroencephalographic characteristics of Dravet syndrome. Epilepsia. 2011;52 Suppl 2: 13-23.

25. Marini C, Scheffer IE, Nabbout R, et al. The genetics of Dravet syndrome. Epilepsia. 2011;52 Suppl 2:24-9.

26. Marini C, Mei D, Parmeggiani L, et al. Protocadherin 19 mutations in girls with infantile-onset epilepsy. Neurology. 2010;75: 646-53.

27. Scheffer IE, Turner SJ, Dibbens LM, et al. Epilepsy and mental retardation limited to females: an under-recognized disorder. Brain. 2008;131:918-27.

28. Depienne C, Bouteiller D, Keren B, et al. Sporadic infantile epileptic encephalopathy caused by mutations in PCDH19 resembles Dravet syndrome but mainly affects females. PLoS Genet. 2009;5:e1000381.

29. Chiron C, Dulac O. The pharmacologic treatment of Dravet syndrome. Epilepsia. 2011;52 Suppl 2:72-5.

30. Gospe SM, Jr. Neonatal vitamin-responsive epileptic encephalopathies. Chang Gung Med J. 2010;33:1-12.

31. Liang JS, Shimojima K, Takayama R, et al. CDKL5 alterations lead to early epileptic encephalopathy in both genders. Epilepsia. 2011;52:1835-42.

32. Bahi-Buisson N, Nectoux J, Rosas-Vargas H, et al. Key clinical features to identify girls with CDKL5 mutations. Brain. 2008; 131:2647-61.

33. Guerrini R, Moro F, Kato M, et al. Expansion of the first PolyA tract of ARX causes infantile spasms and status dystonicus. Neurology. 2007;69:427-33.

34. Klein KM, Yendle SC, Harvey AS, et al. A distinctive seizure type in patients with CDKL5 mutations: Hypermotor-tonic-spasms sequence. Neurology. 2011;76:1436-8.

35. Prasad AN, Rupar CA, Prasad C. Methylenetetrahydrofolate reductase (MTHFR) deficiency and infantile epilepsy. Brain Dev. 2011;33:758-69.

36. Stockler S, Plecko B, Gospe SM Jr, et al. Pyridoxine dependent epilepsy and antiquitin deficiency: clinical and molecular 
characteristics and recommendations for diagnosis, treatment and follow-up. Mol Genet Metab. 2011;104:48-60.

37. Mastrangelo M, Leuzzi V. Genes of early-onset epileptic encephalopathies: from genotype to phenotype. Pediatr Neurol. 2012;46:24-31.

38. Ottman R, Hirose S, Jain S, et al. Genetic testing in the epilepsies-report of the ILAE Genetics Commission. Epilepsia. 2010; 51:655-70

39. Harkin LA, McMahon JM, Iona X, et al. The spectrum of SCN1Arelated infantile epileptic encephalopathies. Brain. 2007;130: 843-52.

40. Saitsu H, Kato M, Okada I, et al. STXBP1 mutations in early infantile epileptic encephalopathy with suppression-burst pattern. Epilepsia. 2010;51:2397-405.
41. Mulley JC, Mefford HC. Epilepsy and the new cytogenetics. Epilepsia. 2011;52:423-32.

42. Miller DT, Adam MP, Aradhya S, et al. Consensus statement: chromosomal microarray is a first-tier clinical diagnostic test for individuals with developmental disabilities or congenital anomalies. Am J Hum Genet. 2010;86:749-64.

43. Mefford HC, Yendle SC, Hsu C, et al. Rare copy number variants are an important cause of epileptic encephalopathies. Ann Neurol. 2011;70:974-85.

44. Paciorkowski AR, Thio LL, Rosenfeld JA, et al. Copy number variants and infantile spasms: evidence for abnormalities in ventral forebrain development and pathways of synaptic function. Eur J Hum Genet. 2011;19:1238-45. 